\title{
BMJ
}

\section{Prevalence of severe congenital heart disease after folic acid fortification of grain products: time trend analysis in Quebec, Canada}

\author{
Raluca Ionescu-Ittu, PhD candidate, ${ }^{1}$ Ariane J Marelli, associate professor of medicine, ${ }^{2}$ director, ${ }^{3}$ \\ Andrew S Mackie, assistant professor of paediatrics, ${ }^{4}$ Louise Pilote, professor of medicine, ${ }^{2}$ director $^{5}$
}

1Department of Epidemiology, Biostatistics and Occupational Health, McGill University, Montreal, Canada

${ }^{2}$ McGill University, Montreal, Canada

${ }^{3}$ McGill Adult Unit for Congenital Heart Disease Excellence

(MAUDE), McGill University Health Centre, Montreal, Canada

${ }^{4}$ University of Alberta, Division of Cardiology, Stollery Children's Hospital, Edmonton, Canada

${ }^{5}$ Division of General Internal Medicine, McGill University Health Centre, Montreal, Canada

Correspondence to: L Pilote, Royal Victoria Hospital, V Building, 687 Pine Avenue West, Room V2.17, Montreal, QC, Canada H3A 1A1

louise.pilote@mcgill.ca

Cite this as: $B M / 2009 ; 338: b 1673$ doi:10.1136/bmi.b1673

\section{ABSTRACT}

Objective To investigate whether the 1998 government policy for mandatory fortification of flour and pasta products with folate was followed by a reduction in the prevalence of severe congenital heart defects.

Design Time trend analysis.

Setting Province of Quebec, Canada.

Participants Infants born in 1990-2005 identified with severe congenital heart defects (tetralogy of Fallot, endocardial cushion defects, univentricular hearts, truncus arteriosus, or transposition complexes) in Quebec administrative databases.

Methods Data analysed in two time periods (before and after fortification). Birth prevalence measured annually as infants (live and stillbirths) with severe congenital heart defects per 1000 births in Quebec. Changes in the birth prevalence from the period before to the period after fortification were estimated with Poisson regression. Results Among the 1324440 births in Quebec in 19902005 there were 2083 infants born with severe congenital heart defects, corresponding to an average birth prevalence of $1.57 / 1000$ births. Time trend analysis showed no change in the birth prevalence of severe birth defects in the nine years before fortification (rate ratio $1.01,95 \%$ confidence interval 0.99 to 1.03 ), while in the seven years after fortification there was a significant $6 \%$ decrease per year $(0.94,0.90$ to 0.97$)$.

Conclusions Public health measures to increase folic acid intake were followed by a decrease in the birth prevalence of severe congenital heart defects. These findings support the hypothesis that folic acid has a preventive effect on heart defects.

\section{INTRODUCTION}

Folic acid intake around the time of conception reduces the risk of neural tube defects in the newborn..$^{1-3}$ Measures to increase intake of folic acid in this period include multivitamin supplementation ${ }^{4}$ and fortification of grain products such as flour and pasta. $^{56}$ While supplements tend to target only women planning a pregnancy, fortification measures are larger in scope and target all women of childbearing age. Fortification of grain products with folic acid has been mandatory in the Unites States since January $1998^{6}$ and in Canada since December $1998^{5}$ and was followed within months by significant increases in the concentrations of erythrocyte folate among women of childbearing age $\mathrm{e}^{7-10}$ and a decrease in the birth prevalence of neural tube defects. ${ }^{3791112}$

Recent evidence suggests that folic acid might also decrease the birth prevalence of congenital heart defects, ${ }^{13-20}$ the most common of all birth defects. ${ }^{2122}$ The existing evidence for an association between folic acid and congenital heart defects, however, is still inconclusive. ${ }^{20}$ In 2007, a statement from the American Heart Association Council emphasised the importance of this possible association and the need for corroborative evidence from population based studies. ${ }^{20}$

We assessed, on a population level, the impact of folic acid fortification policies on the birth prevalence of severe congenital heart defects in Quebec, Canada.

\section{METHODS}

Data sources

We identified infants born with severe congenital heart defects in Quebec from 1990 to 2005 using provincial administrative databases that record all contacts between Quebec residents and the medical system since 1983. We used three administrative databases and specific selection algorithms to capture live births and stillbirths. To identify live infants born with severe congenital heart defects, we used diagnostic and procedural codes for severe congenital heart defects recorded in the physicians' claims database of Quebec or the hospital discharge summary database of Quebec, or both. ${ }^{23}$ Infants with severe congenital heart defects who die immediately after birth might not be captured in these databases because there is a waiting time of up to several weeks until the infant is issued a permanent Medicare number. Furthermore, the waiting time for being issued a permanent Medicare number has decreased over time. Consequently, to avoid a possible detection bias in time trends, we decided to rely solely on the Quebec death registry to identify infant deaths due to severe congenital heart defects. 
The death registry probably has complete coverage of infant deaths caused by severe congenital heart defects because the law requires that all sudden or unexpected deaths in infants be subject to autopsy and that the physician or coroner, or both, provide detailed evidence of death. The death registry also records the cause of death for stillbirths, defined as delivery of a fetus of $500 \mathrm{~g}$ or more that died before birth. ${ }^{24}$ This process did not change during the study period. Therefore, we also included in our analyses stillbirths caused by severe congenital heart defects. All three administrative databases use diagnostic codes that conform to ICD-9 (international classification of diseases, ninth revision), except for the death registry, which switched to the 10th revision in 2000 .

In accordance with received ethical approval, the anonymity of patients was preserved. Specifically, patients were identified in the physicians' claims and hospital discharge summary databases using scrambled Medicare numbers as a unique identifier, while data on infant deaths and stillbirths were delivered to us in the form of annual and monthly statistics rounded to a multiple of five. Information on the annual number of live births in Quebec for 19902005 was retrieved from Statistics Canada reports. ${ }^{25}$

\section{Study population}

The study population includes all births (live births and stillbirths) in Quebec from 1990 to 2005 of infants with severe congenital heart defects identified from administrative databases with complete population coverage. The term "severe congenital heart defects" included tetralogy of Fallot, endocardial cushion defects, univentricular hearts, truncus arteriosus, and transposition complexes. Table 1 presents the diagnostic and procedural codes used to identify severe congenital heart defects in the three databases. Patients with severe congenital heart defects were further grouped into those with or without conotruncal defects, defined as teratology of Fallot, truncus arteriosus, and transposition complexes.

While previous studies have suggested that folic acid might also have a protective effect on non-severe

Table 1/Case definitions of severe congenital heart disease by diagnostic codes and surgical procedure codes, or both

\begin{tabular}{|c|c|c|c|}
\hline \multirow[b]{2}{*}{ Diagnosis } & \multicolumn{2}{|c|}{ Diagnostic codes } & \multirow{2}{*}{$\begin{array}{c}\text { Surgical } \\
\text { procedures codes }\end{array}$} \\
\hline & ICD-9* & ICD-10† & \\
\hline $\begin{array}{l}\text { Endocardial cushion } \\
\text { defect }\end{array}$ & 7456 & Q212 & $\begin{array}{l}\text { Atrioventricular } \\
\text { canal repair }\end{array}$ \\
\hline Tetralogy of Fallot & 7452 & Q213, Q201 & Fallot repair \\
\hline Univentricular hearts & $\begin{array}{l}7453 \\
7467\end{array}$ & Q204, Q234 & Fontan procedure \\
\hline $\begin{array}{l}\text { Transposition } \\
\text { complex }\end{array}$ & 7451 & Q203, Q205 & Atrial/arterial switch \\
\hline Truncus arteriosus & 7450 & Q200 & - \\
\hline \multicolumn{4}{|c|}{$\begin{array}{l}\text { *Billed by cardiologist, cardiovascular surgeon in physician's claims } \\
\text { database, during hospital admission in database, or recorded as main } \\
\text { cause of death on death certificate in death registry database. } \\
\text { †Recorded as main cause of death on death certificate in death registry } \\
\text { database. } \\
\text { †Billed by cardiovascular surgeon in physician's claims database. }\end{array}$} \\
\hline
\end{tabular}

congenital heart defects, ${ }^{2026}$ we restricted our analyses to severe defects because detection of mild lesions could be affected by ascertainment bias. Indeed, the detection of mild lesions has increased over time because of the availability of non-invasive detection methods such as cardiac ultrasonography. ${ }^{23}$ On the other hand, severe congenital heart defects have early clinical manifestations that require further investigations, both invasive (cardiac catheterisation) and noninvasive (cardiac ultrasonography), and therefore are not likely to be affected by ascertainment bias.

\section{Case definition}

We identified live births in the physicians' claims and hospitalisation databases and included them in the study if they had diagnostic code or procedural code for a congenital heart defect billed in the first three years of life, and they also had a code for severe congenital heart defects at any time during follow-up in the database. The diagnostic codes in the physicians' claims database were considered valid if billed by a cardiologist or a cardiovascular surgeon, while the procedural codes were considered valid if billed by a cardiovascular surgeon. ${ }^{23}$ Patients who had at least one valid billing for a severe conotruncal defect were classified as having a conotruncal defect; otherwise they were classified as having a non-conotruncal defect.

We identified infant deaths and stillbirths due to severe congenital heart defects in the death registry and included them in the study if a diagnosis code for severe congenital heart defects was recorded as the main cause of death on the death certificate. If the main cause of death was a conotruncal defect, the infant was classified accordingly.

\section{Study design}

We performed a time trend analysis to estimate the change in birth prevalence of severe congenital heart defects before and after the implementation of mandatory folic acid fortification of grain products in Canada in 1998.

\section{Folate fortification and study periods}

The 16 year period covered by this study, 1990-2005, covers the time of all major folic acid interventions implemented in Canada for the prevention of neural tube defects. The first folic acid measure, in 1993, was a policy paper by the Society of Obstetricians and Gynecologists of Canada that recommended that physicians advise women planning a pregnancy to take daily multivitamin supplements including $0.4-1.0 \mathrm{mg}$ of folic acid. ${ }^{4}$ Yet many women either do not plan their pregnancies or do not take multivitamin supplements when planning a pregnancy. ${ }^{2728}$ These women can, however, be targeted indirectly by increasing the folic acid content of basic food products such as flour and pasta. Consequently, the US and Canadian governments amended their legislations in March 1996 and November 1996, respectively, to require the 
mandatory fortification with folic acid of all flour and pasta products, and each government offered the industry two years to comply with the new policy. ${ }^{56}$ The effective deadlines for implementation were January 1998 in the US and December 1998 in Canada. ${ }^{56}$ Reports from the industry ${ }^{10}$ suggest that fortification in the US was largely completed within 15 months of the announcement of the new policy. The target daily intake with the fortification policy was significantly lower than that with multivitamin supplementation (up to $1 \mathrm{mg}$ /day) because higher intakes might mask vitamin B-12 deficiency in older people..$^{9}$

For the purposes of our time series analyses we divided the study period into two periods, before and after fortification. The cut off between the two periods in Canada was set at 1 January 1999, after we applied two lag times: a 15 month lag time between the announcement of the policy and its implementation and a nine month lag time between conception, when exposure to folic acid is likely to have an impact on the heart formation, ${ }^{29-31}$ and birth. Although the 15 month lag time between announcement of the policy and its implementation was reported in the US, ${ }^{10}$ we considered that it is reasonable to assume a similar lag time in Canada. Indeed, the folic acid policy in Canada closely followed the one in the US, and the two countries share a competitive market, supporting this assumption. Similarly, our choice of a nine month lag time between conception and birth is based on existing evidence from Quebec that suggests that over $87 \%$ of deliveries in Quebec were at term during the study period..$^{32}$ The period before fortification therefore covered the nine year period from 1 January 1990 to 31 December 1998, while the period after fortification covered the seven year period from 1 January 1999 to 31 December 2005.

\section{Statistical analysis}

The birth prevalence of severe congenital heart defects was determined annually as the number of infants (live births and stillbirths) born with severe congenital heart defects per 1000 births in Quebec. Descriptive analyses include reports of the average birth prevalence over the whole study period and in the periods before and after fortification. Given that the average birth prevalence over a longer period of time can mask significant secular trends in that period, we conducted time series analyses that focus on the observed and expected time trends in the two periods. Specifically, we estimated the observed time trends in the period before and after fortification in a Poisson regression model with the annual birth prevalence as the dependent variable and the calendar year (birth year) as the independent variable. We estimated the expected time trend in the period after fortification by applying the estimates from the Poisson model in the period before fortification to the calendar years from the period after fortification. From these analyses we report rate ratios and $95 \%$ confidence intervals, where the rate ratios represent the annual change in birth prevalence of severe congenital heart defects in the two periods. Finally, we tested whether the change in time trend from the first period to the second was significant by adding to the Poisson model an interaction term between the binary variable "period" (before/after fortification) and the calendar time variable. The interaction was interpreted as a significant change in the time trend from the period before to the period after fortification if the $\mathrm{P}$ value of the interaction term was below 0.05 . The analyses were repeated for conotruncal and non-conotruncal defects. Analyses were performed with SAS statistical software (version 8.02, Cary, NC).

\section{Follow-up period}

To extend our follow-up period, we included infants born in 2005. Because most infants born with severe congenital heart defects are identified in the first year of life, however, some infants born in 2005 might have been missed, depending on the month of birth. We therefore corrected the birth prevalence in year 2005 using an adjustment procedure that is based on the age specific detection rates for congenital heart defects from the birth cohorts with a complete three year follow-up.

The adjustment method involved three steps. Firstly, we used the observed births in years with complete data to estimate the probability of an infant being identified with congenital heart defects in the database before each age, measured in months, from the first month of life to the 12th month of life. Secondly, we sorted the observed number of infants born in 2005 by age (in months) on 31 December 2005. Finally, we divided the age specific number of observed births from step 2 by the age specific probabilities from step 1 to estimate the total number of observed and unobserved births. The adjustment procedure showed that we needed to add 11 infants to 2005, which increased the birth prevalence in 2005 from $0.94 / 1000$ births before adjustment to $1.08 / 1000$ births after adjustment.

To determine whether any decrease in observed prevalence remained significant we also performed a sensitivity analysis in which we excluded 2005, which required the adjustment as described above.

\section{RESULTS}

\section{Birth prevalence of severe congenital heart defects}

During the study period there were 1324440 births in Quebec and 2083 infants born with severe congenital heart defects, corresponding to an average birth prevalence of $1.57 / 1000$ births. The annual birth prevalence of severe congenital heart defects ranged from 1.08 to 1.81 cases per 1000 births (interquartile range 1.411.74). The average birth prevalence of severe congenital heart defects in the nine years before fortification was slightly higher than the average birth prevalence in the period after fortification (average rate ratio 1.64/ 1000 (95\% confidence interval 1.55 to 1.73$) v 1.47 /$ 1000 (1.37 to 1.58$)$, table 2).

Time trends in birth prevalence of severe congenital heart defects

The time trend analysis showed that there was no change in the birth prevalence of severe congenital heart defects in the period before fortification (time 
Table 2 |Changes in birth prevalence of severe, conotruncal and non-conotruncal, congenital heart defects (CHD) before (1990-8) and after (1999-2005) mandatory fortification of flour and pasta products with folic acid. Birth prevalence shown with $95 \%$ confidence intervals

\begin{tabular}{|c|c|c|c|}
\hline & Severe CHD & Conotruncal & Non-conotruncal \\
\hline No of cases & $2083^{*}$ & 1248 & 832 \\
\hline \multicolumn{4}{|c|}{ Birth prevalence/1000 births: } \\
\hline Before fortification & $1.64(1.55$ to 1.73$)$ & 0.97 (0.91 to 1.04$)$ & 0.67 (0.61 to 0.72$)$ \\
\hline After fortification & $1.47(1.37$ to 1.58$)$ & 0.90 (0.82 to 0.98$)$ & $0.57(0.51$ to 0.64$)$ \\
\hline \multicolumn{4}{|c|}{ Yearly change in birth prevalence: } \\
\hline Before fortification & $0.8(-1.3$ to 3.0$)$ & $2.5(-0.3$ to 5.3$)$ & $-1.5(-4.7$ to 1.8$)$ \\
\hline After fortification & $-6.2(-9.5$ to -2.9$)$ & $-5.2(-9.3$ to -0.7$)$ & $-8.8(-13.8$ to -3.4$)$ \\
\hline $\begin{array}{l}\text { P value period-year } \\
\text { interaction }\end{array}$ & 0.0005 & 0.004 & 0.02 \\
\hline
\end{tabular}

*Total number of severe cases does not exactly match sum of conotruncal and non-conotruncal cases because annual statistics on infant deaths and stillbirths provided by Quebec Death Registry were rounded to multiple of five (see text). trend rate ratio $1.008,0.987$ to 1.030$)$, while the period after the mandatory fortification of flour and pasta with folic acid was accompanied by a $6.2 \%$ decrease per year in birth prevalence $(0.938,0.905$ to 0.971$)$ (figure, table 2). The interaction between period (before/after fortification) and calendar year was significant $(\mathrm{P}<0.001)$, suggesting that the decreasing trend after the flour fortification did not occur by chance.

Birth prevalence of conotruncal and non-conotruncal defects

Infants with conotruncal pathology accounted for $60 \%$ of the study population (1248 infants), including 783 born in the period before fortification and 465 born in the period after fortification. Over the 16 year study period, the average birth prevalence of conotruncal defects was $0.94 / 1000$ and the average birth prevalence of non-conotruncal defects was 0.62/ 1000. The annual birth prevalence of conotruncal defects ranged from 0.70 to 1.14 cases per 1000 births (interquartile range 0.85-1.05); and the annual birth prevalence of non-conotruncal defects ranged from 0.34 to 0.85 cases per 1000 births $(0.54-0.71)$. The average birth prevalence of both conotruncal and non-conotruncal defects was higher in the period before fortification than in the period after fortification (table 2).

Time trends in conotruncal and non-conotruncal defects Time trend analysis for specific lesions showed trends similar to those observed for all severe congenital heart defects. For conotruncal defects we observed a slight $2.5 \%$ increase per year in birth prevalence in the period before fortification (time trend rate ratio 1.025, 0.997 to 1.053) that was curved downward in the period after fortification $(0.948,0.907$ to 0.993$)$, while for non-conotruncal defects there was no change in the period before fortification $(0.985,0.953$ to 1.018$)$ followed by a decrease in the period after fortification $(0.912$, 0.862 to 0.966 ) (table 2). The change in time trend between the two periods was significant for both conotruncal defects $(\mathrm{P}=0.004$ for interaction $)$ and non-conotruncal defects $(\mathrm{P}=0.02)$.

\section{Sensitivity analysis}

When we excluded from the analyses the 83 infants with congenital heart disease born in 2005 there was minimal change in the results. Specifically, the average birth prevalence in the period after fortification increased slightly from 1.47 to 1.54 cases/1000 births, but remained below the birth prevalence in the period before fortification (1.64/1000 births). Similarly, the decreasing time trend in the period after fortification decreased in magnitude, but remained significant $(0.954,0.913$ to 0.997$)$, while the interaction term also remained significant $(\mathrm{P}=0.03)$ (figure, bottom). Removal of data from 2005 had a more important impact on the lesion specific analyses, in which the trends of both conotruncal and non-conotruncal defects after fortification were no longer significant $(0.962,0.909$ to 1.018 , and $0.943,0.879$ to 1.011 , respectively). The interaction term for conotruncal defects remained significant $(\mathrm{P}=0.05)$, although lost its significance for non-conotruncal defects $(\mathrm{P}=0.27)$.

\section{DISCUSSION}

Our population based study shows that fortification of grain products with folic acid in Canada was followed by a significant decrease in the birth prevalence of severe congenital heart defects, supporting the hypothesis that folic acid intake in the period around conception reduces the birth prevalence of severe congenital heart defects. Specifically, we observed that the birth prevalence did not change in the eight years before fortification and decreased in the seven years after fortification. The change in time trend between the two periods was significant both overall and for conotruncal defects and non-conotruncal defects. There were minimal changes in the estimates for the time trends in the sensitivity analyses in which we excluded data from 2005

Our population based study adds to existing evidence from other study designs ${ }^{13-20}$ that, to date, was inconclusive. ${ }^{20}$ In 2007 a scientific statement from the American Heart Association Council emphasised the importance of corroborating the existing evidence with evidence from population based studies. ${ }^{20}$

\section{Strengths and weaknesses}

While the use of administrative databases gave our study its main strength - allowing us to collect data at a population level-it is also a limitation. Firstly, administrative databases for medical claims are known to be prone to misclassification and lack of specificity. ${ }^{33}$ To minimise misclassification errors, we developed a systematic algorithm that cross referenced diagnostic codes recorded in different administrative databases. ${ }^{23}$ Secondly, we identified affected infants in the medical claims database according to the presence of records of congenital heart defects in the database. Therefore, the longer a person was alive during the years covered by the database, the higher the chances of them being captured in the database. To minimise the detection bias that would arise from using different follow-up times, we chose a case 
definition in which all subjects were given the same period of time - from birth to age 3 - to be identified. Thirdly, the annual and monthly statistics on infant deaths and stillbirths due to severe congenital heart defects were rounded to a multiple of five to preserve patients' anonymity. We addressed this limitation by combining the information from the rounded statistics by year and by month to obtain more accurate monthly estimates. More importantly, the rounding is not likely to change the annual trends. Indeed, the rounded trends showed a decrease in infant deaths due to severe congenital heart defects, which is consistent with the continuous advancements in surgical repairs that are likely to increase the survival of newborns with severe congenital heart defects. ${ }^{34}$ Fourthly, stillbirths and infant deaths in those with severe congenital heart defects were identified according to the diagnostic code recorded on the death certificate as the main cause of death. It is unlikely that many infants with severe congenital heart defects have died from other problems. Fifthly, using administrative data we could not measure directly the changes over time in other risk factors for severe congenital heart defects, which might have confounded the observed temporal changes in birth prevalence. However, we succeeded in finding indirect information on most risk factors for severe congenital heart defects that are currently known $^{20}$ (see below). Finally, in the absence of any

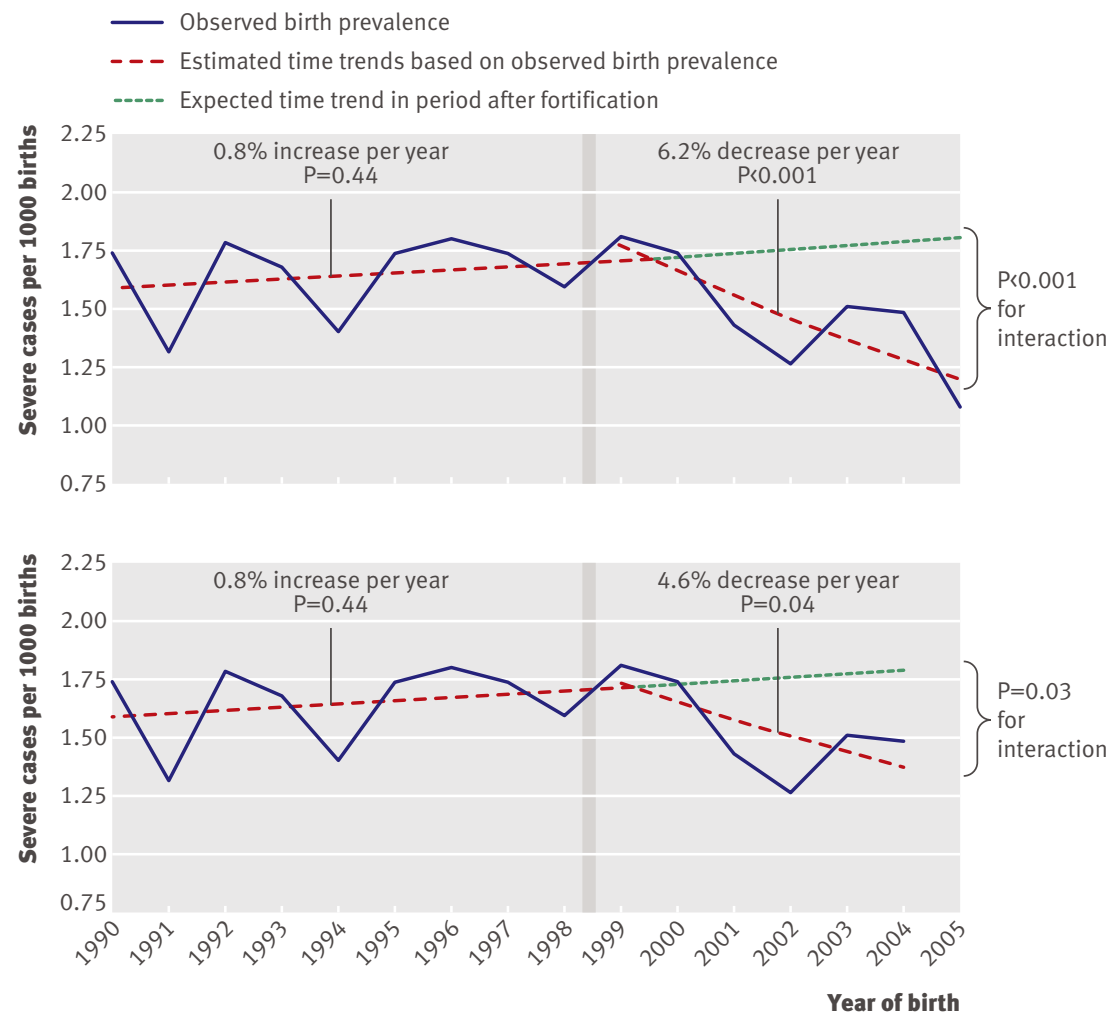

Time trends in birth prevalence of severe congenital heart disease before and after 1 January 1999 cut off (see methods) representing introduction of mandatory fortification of flour and pasta products with folic acid (vertical grey bars), including (top) and excluding (bottom, sensitivity analysis) year 2005 . Time trends estimated in each period by Poisson regression with calendar time as independent variable data on the timeline of the implementation of the new folate policy in Canada, we had to rely on indirect data from the US to establish a lag time between the announcement of the policy and its implementation. Although the cut-off point between the two periods might have been misclassified by several months, this would probably bias the post-fortification trend towards the null and reduce our ability to detect an interaction, thus resulting in more conservative estimates.

Notwithstanding these limitations, our birth prevalence estimates (1.08 to $1.81 / 1000)$ are consistent with estimates from other studies (1.5/1000 live births from the New England Regional Infant Cardiac Program ${ }^{35}$ and 1.71/1000 in the Atlanta metropolitan registry ${ }^{36}$ ), making us confident that our approach has indeed maximised the accuracy and completeness of the data. Given that this is the only population based study to investigate the association between folic acid and severe congenital heart defects and the only time series analysis of this research question, we cannot compare our results directly with results from other studies. The strongest evidence to date for the association between folic acid and congenital heart defects comes from a randomised clinical trial ${ }^{37}$ in which the presence of severe congenital heart defects was a secondary outcome. The trial was the first study to report an association between folic acid and congenital heart defects and showed that women taking multivitamins with $0.8 \mathrm{mg}$ of folic acid had a $58 \%$ reduction in the birth prevalence of congenital heart defects (rate ratio $0.42,0.19$ to 0.98 ) and a $71 \%$ reduction in the birth prevalence of conotruncal defects $(0.29,0.09$ to 0.97). ${ }^{3738}$ Perhaps the most likely explanation for why the effect detected in that trial is much stronger than the one we detected is that the dose of folic acid in multivitamin supplements is significantly higher than the target dose with fortification. Also, that trial was performed in Hungary, and, because of possible differences in dietary folic intake at baseline, their results might not be generalisable. Additional evidence from several case-control studies ${ }^{39-41}$ and some studies on pregnant women taking drugs that are folic acid antagonists $^{4243}$ is contradictory, probably because of selection bias, recall bias, ${ }^{445}$ or misclassifications in quantifying the total folic acid intake by the pregnant women.

\section{Biological mechanisms}

Folic acid might have a role in the migration of the cardiac neural crest cells that contribute to the formation of the truncus arteriosus and its division into the aorta and pulmonary artery, ${ }^{3031}$ thus probably affecting the conotruncal defects in particular. The precise role of folate supplementation on cardiac morphogenesis, however, remains unclear, ${ }^{3031}$ so it is important to corroborate this hypothesis with evidence from clinical and population based studies. To date, the hypothesis is supported by the Hungarian randomised trial ${ }^{3738}$ and several case-control studies, ${ }^{39}{ }^{40}$ but not by other case-control studies ${ }^{41}$ nor by our population based 


\section{WHAT IS ALREADY KNOWN ON THIS TOPIC}

Animal studies show that folic acid might prevent congenital heart defects

Evidence from one randomised controlled trial and several case-control studies is supportive but inconclusive

Evidence from population based studies is lacking

\section{WHAT THIS STUDY ADDS}

The birth prevalence of severe congenital heart defects in Quebec, Canada, decreased after the implementation of a public health policy to increase the folic acid intake at the population level

This population based study supports previous evidence that intake of folic acid around conception has a preventive effect on congenital heart defects

study. Indeed, in our study the folate fortification was followed by a reduction in the birth prevalence of both conotruncal and non-conotruncal defects, although the change in trend for non-conotruncal defects became non-significant in the sensitivity analyses that excluded data from 2005. The subgroup with non-conotruncal defects in our study, however, was smaller than the one with conotruncal defects, so when we deleted these data in the sensitivity analyses the analysis might have simply become too underpowered to detect an effect. Consequently, we believe that there is not enough evidence to rule out a possible effect in nonconotruncal defects.

An average $6.2 \%$ reduction per year $(4.6 \%$ in the sensitivity analysis without data from 2005) in the birth prevalence of severe congenital heart defects observed in this study might seem modest. However, given that severe congenital heart defects require complex surgical interventions in infancy and are associated with high infant mortality rates, ${ }^{46}$ even a small reduction in the overall risk will significantly reduce the costs associated with the medical care of these patients and the psychological burden on patients and their families. We might have underestimated the true impact of folic acid on the birth prevalence of severe congenital heart defects. Specifically, any misclassification of the cut-off point that separates the period before fortification from the period after fortification is likely to bias towards the null the estimate in the period after fortification. Furthermore, by conducting a population based study, the effect is averaged across women who do and do not benefit from the fortification measure. Indeed, women taking multivitamin supplementation are exposed to a high dose of folic acid ( 0.4 to $>1.0 \mathrm{mg} /$ day) and might not benefit from the folic acid fortification measure, which is set at a lower level. ${ }^{5}$ Similarly, women with a low daily intake of bread and pasta might not benefit from dietary fortification.

Finally, our effect might be underestimated because other factors that are known to increase the birth prevalence of congenital heart defects (such as maternal obesity, ${ }^{4748}$ pre-gestational diabetes, ${ }^{4950}$ older maternal age,${ }^{51}$ infants conceived with assisted reproductive technologies, ${ }^{52}$ medication such as antidepressant or angiotensin converting enzyme inhibitors, ${ }^{5354}$ maternal transmission in women with congenital heart defects $^{5556}$ ) have also increased over the study period. Indeed, Canadian reports show that maternal obesity, ${ }^{57}$ diabetes among women, ${ }^{58}$ maternal age ${ }^{59}$ and antidepressant use ${ }^{60}$ and the number of pregnancies in women with congenital heart defects ${ }^{61}$ (who have a 10 -fold higher transmission risk than women in the general population ${ }^{556}$ ) have increased in Quebec over the study period. Although no data on therapeutic abortions related to congenital heart defects were available in Quebec, indirect data from the US shows that prenatal screening for severe birth defects (heart and other) has increased from 70\% in the late 1980 s to $93 \%$ in the late 1990 s, while the percentage of elective terminations among those screened has decreased from $51 \%$ to $44 \%{ }^{62}$ If these trends were similar in Quebec, then the birth prevalence would also be expected to increase. Given that abortion rates are usually culturally sensitive, ${ }^{63}$ the US trends might not apply to Quebec. Still, even if we assume that therapeutic abortions rates have increased in Quebec, the increase would probably have been gradual from one year to another and would not explain the sudden drop in birth prevalence observed in our data immediately after 1998.

Despite the limited descriptive data available to us on concurrent secular trends in other risk factors, we believe that our results are probably not caused by chance because the timing of the observed effect coincides exactly with the timing of the fortification; there is biological plausibility for this association as shown in animal studies ${ }^{3031}$; and, with the exception of natural and elective abortions (on which we have no data from Quebec), all other factors that are known to increase the birth prevalence of severe congenital heart defects, such as older maternal age, more pregnancies in women with congenital heart defects, maternal medication use, or obesity, have gradually increased over the study period in Quebec ${ }^{57-60}$ and, thus, cannot explain the results.

Future population based studies could give more accurate estimates if carried out in areas where data on natural and elective abortions and their outcomes are routinely collected, allowing the modelling of the incidence of severe congenital heart defects, rather than birth prevalence, as the dependent variable. Furthermore, future population based studies with a longer observation time could determine whether the rates stabilise and a saturation point is achieved. Finally, the optimal level of folic acid intake required to achieve a reduction in the birth prevalence of severe congenital heart defects remains unclear, as does the dose-effect relation between the folic acid intake and the birth prevalence of severe congenital heart defects.

Contributors: RI-I contributed to the conception and design of the study analysed the data, interpreted the results, and drafted the manuscript. AJM and ASM acquired the data, interpreted the results, and critically revised the manuscript. LP acquired the data, contributed to the conception and design of the study, interpreted the results, and critically revised the manuscript. LP is guarantor. 
Funding: AJM was funded by the Heart and Stroke Foundation of Canada. ASM is funded by the Fonds de Recherche en Santé du Québec (FRSQ) LP is a senior investigator funded by the FRSQ and James McGill professor of Medicine. The study was funded in part by the Heart and Stroke

foundation of Canada and by the FRSQ

Competing interests: None declared.

Ethical approval: This study was approved by Quebec Commission for Access to Information, the McGill University Health Center ethics board, and the Quebec Statistics Institute. The study is based on administrative databases and subjects were not identifiable to the authors.

1 Rieder MJ. Prevention of neural tube defects with periconceptional folic acid. Clin Perinatol 1994;21:483-503.

2 Pitkin RM. Folate and neural tube defects. Am I Clin Nutr 2007;85:285-8S.

3 De Wals P, Tairou F, Van Allen MI, Uh SH, Lowry RB, Sibbald B, et al. Reduction in neural-tube defects after folic acid fortification in Canada. N Engl J Med 2007:357:135-42.

4 Recommendations on the use of folic acid for the prevention of neural tube defects. J SOGC 1993;(suppl):41-6.

5 Bureau of Food Regulatory, International and Interagency Affairs, Health C. Regulatory impact analysis statement. Canada Gazette Part I/ 1998;132(24):3029-33.

6 Food and Drug Administration. Food Standards. Amendment of standards of identity for enriched grain products to require addition of folic acid. Federal Register 1996;61:8781-96.

7 Ray JG. Folic acid food fortification in Canada. Nutr Rev 2004;62:S35-9.

8 Dietrich M, Brown CJ, Block G. The effect of folate fortification of cereal-grain products on blood folate status, dietary folate intake, and dietary folate sources among adult non-supplement users in the United States. J Am Coll Nutr 2005;24:266-74.

9 Liu S, Longerich L, O'Connor K. Evaluation of food fortification with folic acid for the primary prevention of neural tube defects: executive summary 1997-2003. Public Health Agency of Canada, 2003. www.phac-aspc.gc.ca//publicat/faaf/pdf/folic acid_e.pdf.

10 Jacques PF, Selhub J, Bostom AG, Wilson PW, Rosenberg IH. The effect of folic acid fortification on plasma folate and total homocysteine concentrations. N Engl J Med 1999;340:1449-54

11 Mills JL, Signore C. Neural tube defect rates before and after food fortification with acid. Birth Defects Res A Clin Mol Teratol 2004;70:844-5.

12 Williams LJ, Mai CT, Edmonds LD, Shaw GM, Kirby RS, Hobbs CA, et al. Prevalence of spina bifida and anencephaly during the transition to mandatory folic acid fortification in the United States. Teratology 2002;66:33-9.

13 Acuna J, Yoon P, Erickson D. The prevention of neural tube defects with folic acid. Atlanta, GA: Centers for Disease Control and Prevention, 1999.

14 Health Canada. Congenital anomalies in Canada: a perinatal health report. Ottawa: Minister of Public Works and Governmental Services, 2002.

15 Botto LD, Mulinare J, Erickson JD. Do multivitamin or folic acid supplements reduce the risk for congenital heart defects? Evidence and gaps. Am J Med Genet A 2003;121:95-101.

16 Botto LD, Olney RS, Erickson JD. Vitamin supplements and the risk for congenital anomalies other than neural tube defects. Am J Med Genet C Semin Med Genet 2004:125:12-21.

17 Huhta JC, Hernandez-Robles JA. Homocysteine, folate, and congenital heart defects. Fetal Pediatr Pathol 2005;24:71-9.

18 Bailey LB, Berry RI. Folic acid supplementation and the occurrence of congenital heart defects, orofacial clefts, multiple births, and miscarriage. Am J Clin Nutr 2005;81:1213-7S

19 Huhta JC, Linask K, Bailey L. Recent advances in the prevention of congenital heart disease. Curr Opin Pediatr 2006;18:484-9.

20 Jenkins KJ, Correa A, Feinstein JA, Botto L, Britt AE, Daniels SR, et al. Noninherited risk factors and congenital cardiovascular defects: current knowledge: a scientific statement from the American Heart Association Council on Cardiovascular Disease in the Young: endorsed by the American Academy of Pediatrics. Circulation 2007;115:2995-3014.

21 Minister of Public Works and Government Services. Congenital anomalies in Canada-a perinatal health report, 2002. Ottawa: Health Canada, 2002:15-9.

22 Blomberg M, Selbing A, Kallen B. Congenital malformations in the southeast of Sweden-a registry study with validation. Acta Paediat 2000;89:1238-43.

23 Marelli AJ, Mackie AS, Ionescu-Ittu R, Rahme E, Pilote L. Congenital heart disease in the general population: changing prevalence and age distribution. Circulation 2007:115:163-72.

24 Duchesne L. La situation demographique au Quebec: Bilan 2006. Quebec: Institut de la Statistique du Quebec, 2006:69.
25 Canada S. CANSIM table 053-0001. Vital statistics, births, deaths and marriages, quarterly. Ottawa: Statistics Canada, 2007.

26 Botto LD, Mulinare J, Erickson JD. Occurrence of congenital heart defects in relation to maternal mulitivitamin use. Am J Epidemiol 2000;151:878-84.

27 de Jong-Van den Berg LT, Hernandez-Diaz S, Werler MM, Louik C, Mitchell AA. Trends and predictors of folic acid awareness and periconceptional use in pregnant women. Am J Obstet Gynecol 2005;192:121-8.

28 Tam LE, McDonald SD, Wen SW, Smith GN, Windrim RC, Walker MC. A survey of preconceptional folic acid use in a group of Canadian women. J Obstet Gynaecol Can 2005;27:232-6.

29 Blackburn S. Maternal, fetal and neonatal physiology: a clinical perspective. 3rd ed. Edinburgh: Elsevier Saunders, 2007.

30 Tang LS, Wlodarczyk BJ, Santillano DR, Miranda RC, Finnell RH . Developmental consequences of abnormal folate transport during murine heart morphogenesis. Birth Defects Res A Clin Mol Teratol 2004;70:449-58.

31 Van Beynum IM, Kapusta L, den Heijer M, Vermeulen SH, Kouwenberg M, Daniels 0, et al. Maternal MTHFR 677C)T is a risk factor for congenital heart defects: effect modification by periconceptional folate supplementation. Eur Heart J 2006;27:981-7.

32 Naissances selon la durée de la grossesse et le poids à la naissance, Québec, 1975-2005. Quebec: Institut de la Statistique du Québec, 2007.

33 Jollis JG, Ancukiewicz M, DeLong ER, Pryor DB, Muhlbaier LH, Mark DB. Discordance of databases designed for claims payment versus clinical information systems. Implications for outcomes research. Ann Intern Med 1993;119:844-50.

34 Boneva RS, Botto LD, Moore CA, Yang Q, Correa A, Erickson JD. Mortality associated with congenital heart defects in the United States: trends and racial disparities, 1979-1997. Circulation 2001;103:2376-81.

35 Talner CN. Report of the New England Regional Infant Cardiac Program, by Donald C. Fyler, MD, Pediatrics, 1980;65(suppl):375-461. Pediatrics 1998;102:258-9.

36 Botto LD, Correa A, Erickson ID. Racial and temporal variations in the prevalence of heart defects. Pediatrics 2001;107:E32.

37 Czeizel AE, Dobo M, Vargha P. Hungarian cohort-controlled trial of periconceptional multivitamin supplementation shows a reduction in certain congenital abnormalities. Birth Defects Res A Clin Mol Teratol 2004;70:853-61.

38 Czeizel AE, Merhala Z. Bread fortification with folic acid, vitamin B12, and vitamin B6 in Hungary. Lancet 1998;352:1225.

39 Scanlon KS, Ferencz C, Loffredo CA, Wilson PD, Correa-Villasenor A, Khoury MJ, et al. Preconceptional folate intake and malformations of the cardiac outflow tract. Baltimore-Washington Infant Study Group. Epidemiology 1998;9:95-8.

40 Shaw GM, O'Malley CD, Wasserman CR, Tolarova MM, Lammer E. Maternal periconceptional use of multivitamins and reduced risk for conotruncal heart defects and limb deficiencies among offspring. $\mathrm{Am}$ Med Genet 1995;59:536-45.

41 Werler MM, Hayes C, Louik C, Shapiro S, Mitchell AA. Multivitamin supplementation and risk of birth defects. Am J Epidemiol 1999;150:675-82.

42 Czeizel AE, Rockenbauer M, Sorensen HT, Olsen J. The teratogenic risk of trimethoprim-sulfonamides: a population based case-control study. Reprod Toxicol 2001;15:637-46.

43 Hernandez-Diaz S, Werler MM, Walker AM, Mitchell AA. Folic acid antagonists during pregnancy and the risk of birth defects. N Engl I Med 2000;343:1608-14.

44 Bakker MK, de Walle HE, Dequito A, van den Berg PB, de Jong-van den Berg LT. Selection of controls in case-control studies on materna medication use and risk of birth defects. Birth Defects Res A Clin Mol Teratol 2007;79:652-6.

45 Wacholder S. Design issues in case-control studies. Stat Methods Med Res 1995;4:293-309.

46 Wen SW, Liu S, Joseph KS, Rouleau J, Allen A. Patterns of infant mortality caused by major congenital anomalies. Teratology 2000;61:342-6.

47 Waller DK, Mills JL, Simpson JL, Cunningham GC, Conley MR, Lassman MR, et al. Are obese women at higher risk for producing malformed offspring? Am J Obstet Gynecol 1994;170:541-8.

48 Watkins ML, Botto LD. Maternal prepregnancy weight and congenital heart defects in offspring. Epidemiology 2001:12:439-46.

49 Becerra JE, Khoury MJ, Cordero JF, Erickson JD. Diabetes mellitus during pregnancy and the risks for specific birth defects: a population-based case-control study. Pediatrics 1990;85:1-9.

50 Adams MM, Mulinare J, Dooley K. Risk factors for conotruncal cardiac defects in Atlanta. J Am Coll Cardiol 1989;14:432-42.

51 Reefhuis I, Honein MA. Maternal age and non-chromosomal birth defects, Atlanta-1968-2000: teenager or thirty-something, who is at risk? Birth Defects Res A Clin Mol Teratol 2004;70:572-9. 
52 Hansen M, Kurinczuk JJ, Bower C, Webb S. The risk of major birth defects after intracytoplasmic sperm injection and in vitro fertilization. N Engl J Med 2002;346:725-30.

53 Cooper WO, Hernandez-Diaz S, Arbogast PG, Dudley JA, Dyer S, Gideon PS, et al. Major congenital malformations after first-trimester exposure to ACE inhibitors. N Engl J Med 2006;354:2443-51.

54 Berard A, Ramos E, Rey E, Blais L, St-Andre M, Oraichi D. First trimester exposure to paroxetine and risk of cardiac malformations in infants: the importance of dosage. Birth Defects Res B Dev Reprod Toxicol 2007;80:18-27.

55 Burn J, Brennan P, Little J, Holloway S, Coffey R, Somenille J, et al. Recurrence risks in offspring of adults with major heart defects: results from first cohort of British collaborative study. Lancet 1998;351:311-6.

56 Nora JJ, Nora AH. Maternal transmission of congenital heart diseases: new recurrence risk figures and the questions of cytoplasmic inheritance and vulnerability to teratogens. Am J Cardiol 1987;59:459-63.

57 Mongeau L, Audet N, Aubin J, Baraldi R. L'exces de poids dans la population Quebecoise de 1987 a 2003. Quebec: Institute de la Statistique du Quebec, 2005.
58 Portrait social du Quebec, donnees et analyses. Quebec: Institut de la Statistique du Quebec, 2001.

59 Girard C. Le bilan demographique du Quebec. Quebec: Institut de la Statistique du Quebec, 2007.

60 Ramos E, Oraichi D, Rey E, Blais L, Berard A. Prevalence and predictors of antidepressant use in a cohort of pregnant women. BJOG 2007;114:1055-64.

61 Bottega NA ZS, Ionescu-Ittu R, Therrien J, Martucci G, Pilote L, Marelli AJ. Rising numbers of pregnancies and offspring in women with congenital heart disease: a population-based study. Circulation 2008;118(18, suppl 2):S929.

62 Peller AJ, Westgate MN, Holmes LB. Trends in congenital malformations, 1974-1999: effect of prenatal diagnosis and elective termination. Obstet Gynecol 2004;104:957-64.

63 Garne E, Loane M, Dolk H, De Vigan C, Scarano G, Tucker D, et al. Prenatal diagnosis of severe structural congenital malformations in Europe. Ultrasound Obstet Gynecol 2005;25:6-11.

Accepted: 28 January 2009 